\title{
Evaluation of a culturally appropriate smoking cessation intervention for Latinos
}

\author{
S I Woodruff, G A Talavera, J P Elder
}

Tobacco Control 2002;1 1:361-367

See end of article for authors' affiliations

.....................

Correspondence to: Susan I Woodruff, San Diego State University, Graduate School of Públic Health, 9245 Sky Park Court, Suite 120, San Diego, CA 92123, USA swoodruf@mail.sdsu.edu

Received

20 January 2002

and revision requested 24

July 2002. Accepted 8

September 2002
Background: Many believe that smoking cessation programmes for Latinos should be tailored to the values and beliefs of the culture. However, randomised studies of culturally appropriate smoking cessation interventions with Latinos are rare.

Methods: Latino smokers ( $\mathrm{n}=313$ ) were randomised to an intervention condition or a comparison group. The intervention was a three month programme based on social cognitive constructs and delivered in the smoker's home by trained lay health advisors, or promotores. Comparison group participants were referred to the California Smoker's Helpline in Spanish. Predictors of abstinence among all participants also were examined.

Results: About one week post-intervention, validated (carbon monoxide) past week abstinence rates were more than twice as high in the intervention group $(20.5 \%)$ than in the comparison $(8.7 \%)$ $(p \leqslant 0.005)$. The pattern of results held for self reported abstinence, and after recoding dropouts to non-abstinence. The primary predictor of abstinence was number of cigarettes smoked per day at baseline, a common measure of addiction.

Conclusions: The culturally appropriate intervention facilitated abstinence in Latino smokers, at least in the short term. Strengths and weaknesses of the study are discussed.
$\mathrm{T}$ obacco use causes devastating disease and premature death in every population in the USA, including Latinos. ${ }^{1}$ Current data suggest Latinos smoke at lower rates than non-Hispanic whites, and that among current smokers, Latinos smoke few cigarettes per day. ${ }^{1}$ The 1998 National Health Interview Survey data show that $24.7 \%$ of Latino men and $13.3 \%$ of Latino women smoke. ${ }^{2}$ In California where smoking rates generally are lower than national estimates, the rate is about $21 \%$ for Latino men and $10 \%$ for Latino women. ${ }^{3}$ Despite the lower rates of smoking among Latinos, the issue is likely to become a more important public health concern since Latinos are the fastest growing ethnic minority in the USA, and because acculturation may increase the incidence of cigarette smoking among some Latino groups (for example, women). ${ }^{1}$ Also of concern, past-month smoking increased among Latino adolescents by 34\% from 1991 through 1997, perhaps due in part to targeted advertising and promotion of tobacco products to young ethnic minorities.

Population based surveys in California show that Latino smokers are more likely to be contemplating cessation and may be more likely to make quit attempts than non-Hispanic whites, ${ }^{3}$ yet may be less likely to seek help to quit. ${ }^{4}$ One reason for the low seeking of help might be because of a lack of cessation resources. A survey of available cessation support in the San Diego area by this research team yielded very few resources that were linguistically appropriate, with one of the few being the California's Smokers' Helpline in Spanish. Many believe that in addition to being linguistically appropriate, cessation programmes should also be culturally appropriatethat is, tailored or modified on the basis of the values and beliefs of the ethnic group with which they are to be used..$^{5-7}$ Although certain generic approaches (for example, nicotine patch) may be effective with Latino smokers, ${ }^{5}$ most agree an approach that takes into consideration the cultural attitudes, norms, expectations, and values of the targeted cultural group is likely to increase acceptance of a programme and may enhance effectiveness. ${ }^{5}$

Randomised studies of culturally appropriate smoking cessation interventions with Latinos are rare. One of the few was an assessment of a culturally specific multicomponent behavioural programme with 93 Hispanic smokers in Queens, New York. ${ }^{8}$ Compared to a minimal contact control group, intervention participants showed greater cotinine validated abstinence rates at post-test. However, by the 12 month follow up, quit rates for the two groups had converged.

The purpose of the present study is to add to the scant body of knowledge about effective smoking cessation programmes for Latinos by evaluating the impact of a culturally appropriate smoking cessation intervention implemented in a predominately Latino area of San Diego. The intervention was based on social cognitive constructs and was delivered in the smoker's home by trained lay health advisors, or promotores. Sociodemographic and smoking related predictors of postintervention abstinence are also examined.

\section{METHODS}

\section{Design and participant recruitment}

The study was a randomised, two group trial involving 313 Spanish speaking Latino smokers living in San Diego County. After completing consent forms and a baseline assessment, eligible participants were randomised into either the intervention group or a comparison group using a random number generator. The intervention group received a culturally appropriate three month programme delivered in the home by lay health advisors, or promotores. Participants in the comparison group were referred to the Spanish language California Smokers' Helpline (1-800-45-NO FUME (USA only)) via postcards mailed twice during the intervention period.

Recruitment of participants was primarily conducted by trained recruiters, individuals familiar with the targeted Latino community. Eleven trained recruiters worked at community events, popular neighbourhood shopping centres, and within their own social networks to identify Latino smokers. Screening was conducted using a standard description of the project and a structured eligibility script and screening instrument. Inclusion criteria included self reports of being a current smoker, being at least 18 years of age, ability to write 
and read Spanish, planning to live in the area during the next year, no current participation in another smoking related study, no chemical dependency or psychiatric comorbidity, and not being institutionalised.

\section{Intervention}

Promotor approach, recruitment, and training

The intervention, called "Proyecto Sol", was delivered in the participant's home by lay community health advisors, or promotores. The community health advisor or promotor approach is based on the assumption that within every community there are formal and informal social networks through which health information is exchanged and supportive environments are created. Promotores are "paraprofessionals" who, because they already have existing relationships with their community, are in a unique position to improve community health. ${ }^{9}$ Usually members of existing social networks such as church groups, senior groups, and other social clubs, these individuals often have attributes of leadership, compassion, and familiarity with the community. ${ }^{10}$ The formal use of these community change agents in the USA is growing. ${ }^{12}$ In general, the literature indicates that promotores can increase access to the target audience and improve accessibility to health care resources. ${ }^{12}{ }^{13}$ The approach has been applied in cancer and cardiovascular disease risk reduction programmes for Latinos with promising results, ${ }^{14-16}$ although rigorous evaluations are rare.

Sixteen promotores ( 14 women and 2 men) were recruited by the project. Most ( $85 \%$ ) had worked on previous research and community projects. Promotores were 41 years old on average (range 31-56 years), and had an average education level comparable to a high school diploma. Thirteen of the 16 were born in Mexico, one in the USA, and two in Argentina. Promotores completed 25 hours of training within nine lessons over a five week period. Training included didactic methods, role playing, skills development, motivational interviewing techniques, and ongoing mastery testing of the intervention curriculum. Promotores had different caseloads depending upon their availability and geographic location. They worked with a range of 1-21 intervention participants, with an average of 10 . Promotores were paid modest stipends for their intervention work.

\section{Culturally adapted intervention content}

In addition to the use of promotores to deliver the intervention, the curriculum was modified to address several culturallinguistic barriers for the Latino community. The curriculum was written and delivered in the Spanish language appropriate for the unique population of low literacy individuals along the California border. ${ }^{17}$ Communication style and values congruent with the Latino culture were also considered, including: familismo; collectivism; simpatía; personalismo; and respeto. ${ }^{18}{ }^{19}$ There were distinct theoretical considerations as well in the design of the intervention strategies. The intervention content was based on social cognitive principals including positive reinforcement, stimulus control, modelling, social support, problem solving, and practical skills and techniques for quitting ${ }^{20}$ principals that are congruent with several findings related to smoking among Latinos. Latinos may be less likely to smoke in response to habitual cues rather than social and emotional cues, ${ }^{21-23}$ and appropriate stimulus control techniques were used to address these cues. Social and family concerns, rather than a focus on the individual, were given greater emphasis in the intervention. ${ }^{24}$

Before designing the intervention curriculum, existing cessation materials available in Spanish were reviewed. Two materials were included: a video entitled Me Muero por Fumar (I'm dying to smoke), and a guidebook entitled Rompa con el Vicio: Una Guía para Dejar de Fumar (Breaking the habit: a guide to quitting smoking). ${ }^{25}$ The three month intervention consisted of four home visits and three telephone calls from the assigned promotor. Each home visit was 1-2 hours in length, and telephone calls were typically 15-30 minutes in length. More of the intervention was delivered early in the three months, with contact tapering off toward the end. Timing of the intervention is described below, as is more detail about each home visit. Although the curriculum was specific and structured, attempts were made to allow the promotor and participant some flexibility in timing and content, a potentially important component of culturally appropriate approaches. ${ }^{67}$

The main objectives of the first home visit (day 1 of the intervention) were to establish rapport with the participant, review the goals of the project, and set the stage for maximising success of quitting. The promotor and participant reviewed past quit attempts; discussed the pros and cons of smoking and quitting; discussed self monitoring to identify smoking patterns; identified potential reinforcements and substitute behaviours; and discussed appropriate coping strategies. In addition, the promotor had access to a portable TV/VCR if needed for viewing the video with the participant. The video included well acted realistic scenarios of Latino smokers coping with cessation. Participants were also given the Guía para Dejar de Fumar, which was used throughout the intervention. The Guía is a 24 page, full colour booklet featuring Latino smokers demonstrating challenges to cessation and various cessation techniques, as well as testimonials about quitting.

The second home visit took place about one week later, on day 8 of the intervention. One of the major tasks of the second visit was to motivate the participant to set a quit date. The promotor and participant formulated a specific plan, identifying different smoking cessation techniques. Part of the plan included involving supportive family members and identifying a quit buddy. Participants were given a "quit kit" that included gadgets with the project logo that could serve as behavioural cues, and practical items (for example, toothpicks, chewing gum) that might serve to occupy the hands and mouth. Three days after the second home visit (day 11), the promotor called the participant to assess progress or setbacks, and to provide support during the relapse sensitive stages of the quit process.

The third home visit took place on day 22, two weeks after the second visit. During this visit, the promotor discussed the participant's experiences while quitting smoking, the results of the quit attempt, and assessed the participant's current needs and concerns. The bulk of the visit was focused on relapse prevention and positive reinforcement of the participant's efforts thus far. A second phone call two weeks after the third home visit (day 36) was conducted to once again provide support during the quit process.

The fourth home visit on day 50 of the intervention phase was designed to explore aspects of quitting the participant was finding challenging (for example, weight gain), and to reinforce successes during the previous weeks. It also included a talk about overall lifestyle change (for example, exercise), and different techniques for long term success. A third telephone call followed on day 78. The purpose of the third call was to assess how the participant was doing, to say goodbye, and to encourage staying quit (or to quit again if relapsed). Throughout all visits and telephone contact, participants were encouraged to interpret lapses as learning experiences and part of the quitting process. A recommitment to cessation was encouraged by the promotor using non-judgmental motivational counselling techniques.

\section{Helpline comparison}

The Helpline is an innovative approach to smoking cessation and is promoted free of charge throughout California. Since August 1992, the programme has provided its services in Spanish. Strategies used by the Helpline have continually evolved since its inception, although Helpline characteristics in place at the time of the present study are described here. 
Every caller to the Helpline first receives a six minute screening interview assessing smoking history, dependence, self efficacy, and readiness to quit. After the first call, subsequent structured telephone sessions are initiated by a trained counsellor in a proactive manner (see Zhu and colleagues ${ }^{26}$ for details of the approach and counsellor training). In contrast to traditional schedules, the Helpline uses a method that arranges follow up sessions according to the probability of relapse, thereby providing assistance to the smoker when most needed. The number of sessions varies with as many as six separate calls possible. If all sessions are received, the total counselling time is slightly under three hours. The Helpline has been widely promoted and has achieved a good representation of minority smokers. ${ }^{4}$

\section{Data collection}

At baseline and again approximately one week after the three month intervention phase, a trained bilingual/bicultural measurement technician visited all participants in their homes to collect measures. The measurement technician collected two types of data: (a) self administered paper-andpencil smoking surveys; and (b) expired carbon monoxide (CO). In the present study, CO was used to assess validity of self reports directly, as well as provide respondents with an added incentive to be accurate, as a bogus pipeline procedure.

\section{Measures}

Paper-and-pencil survey measures included self reports of smoking status and history, quit attempts, attitudes and knowledge about smoking and cessation, sociodemographic variables, and acculturation. Measures were either existing standard items, or were developed and translated using a professional translation service with multiple bilingual project staff members assessing the congruence of the items with the English version. Measures developed by staff (for example, smoking attitudes and knowledge) were pilot tested with small convenience samples of Latino adults similar to those targeted for the study.

The outcome measure in the present study was a point prevalence variable representing $\mathrm{CO}$ validated past-week abstinence at the post-intervention assessment ( 0 coded as abstinent, l coded as smoking or non-abstinent). Although CO was collected for all participants at baseline and post-intervention, it was only used to corroborate self reports of abstinence. At baseline, all participants were admitted current smokers, therefore $\mathrm{CO}$ concentrations were not used to categorise them as abstinent or smoking. On the postintervention survey, participants reporting that they had smoked any during the previous seven days were considered non-abstinent. For those reporting no past-week smoking on the survey, $\mathrm{CO}$ concentration was then used to validate self reported abstinence, with concentrations of 8 parts per million (ppm) or greater considered indicative of recent smoking. ${ }^{27} 28$ Participants whose post-intervention self-reports post differed from their $\mathrm{CO}$ measure were assumed to be non-abstinent.

Several sociodemographic and smoking related variables from the baseline survey were used in the present study to describe the sample, assess group equivalence at baseline, and examine as predictors of abstinence. Sociodemographic characteristics included: (a) sex; (b) age in years; (c) marital status (married/living as married versus not married); (d) number of children in the home; (e) monthly household income with response options ranging from 1 (less than $\$ 700$ a month) to 7 (\$2600 or more a month); (f) years of education ranging from 1 (no school or kindergarten only) to 8 (graduate degree); (g) place of birth (Mexico, USA, or elsewhere); and (h) a language based acculturation score computed as the mean of eight items (coefficient $\alpha=0.81$ ) from the ARSMAII, an acculturation rating scale developed by Cuellar and colleagues. $^{29}$
Baseline smoking related variables included: (a) age one first started to smoke fairly regularly; (b) number of years smoking; (c) amount smoked on a typical day during the past 30 days, measured on a scale with response categories ranging from 1 ( 0 cigarettes) to 11 (more than 40 cigarettes on a typical day); (d) minutes to first cigarette of the day, measured on a scale ranging from 1 (immediately after waking) to 6 (more than two hours after waking); (e) CO concentration in ppm, computed as an average of two readings with an ambient concentration subtracted; (f) number of recent quit attempts in the last three months; (g) a smoking and cessation knowledge score based on 15 items, with scores potentially ranging from 0-15; and (h) self efficacy computed as the mean of two items assessing confidence in quitting, with scores ranging from 1 (low self efficacy) to 5 (high self efficacy).

\section{Analysis}

The primary analyses (that is, $\chi^{2}$ ) tested interventioncomparison group differences in $\mathrm{CO}$ validated abstinence at the post-intervention assessment. To provide a conservative estimate of intervention effects, data were analysed: (a) for the longitudinal sample excluding dropouts - that is, for those providing both pre- and post-intervention measures; and (b) with missing cases included and assumed to be smoking during the past week.

To assess potential attrition bias, $t$ tests for independent groups, and interaction terms (attrition status-by-condition) from two way analysis of variance tests were conducted. $\chi^{2}$ Tests, $t$ tests for independent groups, or Mann-Whitney U tests were conducted to assess equivalence between conditions at baseline. To evaluate predictors of abstinence, $\chi^{2}$ tests, $t$ tests for independent groups, and Mann-Whitney $U$ tests were conducted to assess associations at the univariate level, followed by a multivariate analysis (that is, multiple logistic regression) to evaluate independent predictors of abstinence.

\section{RESULTS}

\section{Participant characteristics}

Participants were 313 Latinos living in the Southbay area of San Diego, all of whom were admitted current smokers upon enrolment into the study. Approximately half $(n=156)$ were assigned to the intervention and half $(n=157)$ to the comparison condition. The majority $(n=253)$ were individuals randomly assigned to condition. However, 60 were part of a family with two $(\mathrm{n}=54 ; 27$ households) or three $(\mathrm{n}=6 ; 2$ households) family members participating. In these cases, the index case was randomly assigned to condition and other participants within the family were assigned to the same condition.

Fifty one per cent of the 313 participants were female, and the average age was 42.4 years (SD 12.6). Seventy eight per cent were born in Mexico, 16\% in the USA, and 7\% in South and Central American countries. Approximately 56\% were married or living as married, and $49 \%$ were employed outside the home. The median household income was \$1100-\$1400 a month, low by US standards. Almost half had less than a high school education; the average (median) years of education was 9-11 years. Two thirds reported completing most of their education in Mexico. About 67\% reported having at least one child under 18 years of age living in the household; among those reporting a child in the home, the average (mean) number of children was 2.3 (1.36). Participants had an average (mean) acculturation score of $2.13(0.84)$, with scores potentially ranging from 1 (low acculturation) to 5 (high acculturation). Participants were primarily monolingual Spanish speakers.

Participants smoked 11-15 cigarettes a day on average, with men being slightly heavier smokers than women $(\mathrm{t}[311]=-4.47, \mathrm{p} \leqslant 0.001)$. Participants had started smoking at a median age of 16 years, and typically had been smoking 26 
Table 1 Baseline equivalence between conditions for longitudinal sample $(n=282)$

\begin{tabular}{|c|c|c|c|}
\hline \multirow[b]{2}{*}{ Variable } & \multicolumn{2}{|c|}{$\%$, median, or mean (SD) } & \multirow[b]{2}{*}{$\mathrm{p}$ Value } \\
\hline & $\begin{array}{l}\text { Intervention } \\
(n=132)\end{array}$ & $\begin{array}{l}\text { Comparison } \\
(n=150)\end{array}$ & \\
\hline \multicolumn{4}{|l|}{ Sociodemographic variables } \\
\hline Sex (\% female) & 52 & 48 & $0.07^{*}$ \\
\hline Age in years (mean) & 43 (13.7) & $42(12.2)$ & $0.39 \dagger$ \\
\hline Marital status ( $\%$ married) & 54 & 58 & $0.47^{*}$ \\
\hline Number of children in home (mean) & $1.6(1.6)$ & $1.5(1.5)$ & $0.52^{*}$ \\
\hline Income (median category) & $\$ 1100-1400$ & $\$ 1100-1400$ & $0.57 \dagger$ \\
\hline $\begin{array}{l}\text { Years of education (median category) } \\
\text { Place of birth (\%) }\end{array}$ & $9-11$ years & $9-11$ years & $0.41 \dagger$ \\
\hline Mexico & 77 & 75 & \\
\hline USA & 16 & 17 & \\
\hline Other & 7 & 7 & $0.93^{*}$ \\
\hline Acculturation score (mean) & $2.03(.82)$ & $2.16(.87)$ & $0.17 \dagger$ \\
\hline \multicolumn{4}{|l|}{ Smoking related variables } \\
\hline Age started smoking (mean) & $16.3(2.9)$ & $16.4(2.9)$ & $0.32 \dagger$ \\
\hline Number of years smoking (mean) & $26.8(14.0)$ & $25.4(12.4)$ & $0.36 \dagger$ \\
\hline Amount smoked per day (mean category) $\ddagger$ & $4.7(1.6)$ & $5.1(1.7)$ & $0.08 \dagger$ \\
\hline Minutes to first cig of day (mean category)§ & $3.1(1.9)$ & $3.0(1.9)$ & $0.51 \dagger$ \\
\hline $\mathrm{CO}$ concentration (mean ppm) & $11.5(8.6)$ & $11.7(8.1)$ & $0.81 \dagger$ \\
\hline Number of recent quit attempts (mean) & $1.0(1.5)$ & $1.1(1.6)$ & $0.67 \dagger$ \\
\hline Knowledge score (mean) & 10.7 (1.9) & $10.9(1.9)$ & $0.82 \dagger$ \\
\hline Self efficacy for quitting (mean) & $4.1(1.1)$ & $4.0(1.1)$ & $0.43 \dagger$ \\
\hline \multicolumn{4}{|c|}{$\begin{array}{l}\text { * } \chi^{2} \text { Test. } \\
\dagger t \text { Test or Mann-Whitney U test for two independent groups. } \\
\text { †Response categories included: } 1 \text { (0 cigarettes), } 2 \text { (<1 cigarette), } 3 \text { (1-5 cigarettes), } 4 \text { (6-10 cigarettes), } \\
5 \text { ( } 11-15 \text { cigarettes), } 6 \text { ( } 16-20 \text { cigarettes), } 7 \text { ( } 21-25 \text { cigarettes), } 8 \text { (26-30 cigarettes), } 9 \text { (31-35 cigarettes), } \\
10 \text { ( } 36-40 \text { cigarettes) and } 11 \text { (> } 40 \text { cigarettes on a typical day). } \\
\text { §Response categories included: } 1 \text { (immediately after waking), } 2 \text { (within } 15 \text { minutes of waking), } 3 \text { (15-30 } \\
\text { minutes after waking), } 4 \text { ( } 31-60 \text { minutes after waking), } 5 \text { (61 minutes to } 2 \text { hours after waking), and } 6 \text { (>2 } \\
\text { hours after waking). } \\
\text { CO, carbon monoxide. }\end{array}$} \\
\hline
\end{tabular}

years. They reported usually having their first cigarette of the day 15-30 minutes after waking. Eighty one per cent reported ever having tried to quit; $43 \%$ had quit for a day or longer within the past three months. Smoking/cessation related knowledge was relatively high (a score of 10.8 on a 15 point scale), as was self efficacy for quitting (score of 4.0 on five point scale).

\section{Attrition and baseline equivalence between groups}

Thirty one participants (9.9\% of the total) did not complete the post-intervention assessment and were considered dropouts, resulting in a longitudinal sample of 282 participants. Rates were significantly different by condition, with $4.5 \%$ of comparison group participants dropping out versus $15.4 \%$ of the intervention participants $\left(\chi^{2}[1]=10.47, p \leqslant 0.001\right)$. Rather than the rate of attrition, the more important question in terms of validity is a test of whether the characteristics of those who dropped out versus those who continued to participate differed by condition. ${ }^{30}$ Two way analysis of variance tests (that is, testing of the attrition status-by-condition interaction) and non-parametric equivalent tests on sociodemographic and baseline smoking related variables showed no differential attrition by condition: dropouts were similar in both conditions with regard to sex, age, marital status, acculturation level, number of children in household, place of birth, income, education, baseline self reported smoking variables, baseline CO concentration, baseline quitting history, smoking/ cessation knowledge, and self efficacy. However, analysis showed that, in both conditions, dropouts were significantly different from those who remained on two of the 16 variables: dropouts had slightly higher acculturation scores $(\mathrm{t}[311]=-1.95, \quad \mathrm{p} \leqslant 0.05 ; \quad$ Mann-Whitney $\quad \mathrm{U}=3051$, $\mathrm{p} \leqslant 0.01)$ and higher education levels $(\mathrm{t}[311]=-2.58$, $p \leqslant 0.01)$ than those who continued to participate. In summary, the internal validity of the study was not compromised by attrition, although generalisation (that is, external validity) of study results to higher acculturated and educated Latino smokers may be limited.

Analyses on all 313 participants showed that the intervention and comparison groups did not differ on any sociodemographic and baseline smoking related variable tested (data not shown), confirming the success of the randomisation process. Similar comparisons were made for the longitudinal sample $(n=282)$. As shown in table 1 , groups were equivalent on most sociodemographic and smoking related variables. There was a tendency for the intervention group to have more women and slightly lighter smokers than the comparison group, although group differences were small and did not reach significance at the 0.05 level.

\section{Abstinence at post-intervention}

As shown in table 2, conditions differed significantly in pastweek smoking abstinence at the post-intervention assessment. Among the longitudinal sample, about $21 \%$ of the intervention group self reported that they had abstained during the previous week, compared to $11 \%$ in the comparison group. CO and self reports were discrepant for only five individuals, four of whom were in the comparison group. In all five cases, CO concentrations indicated recent smoking, while self reports indicated abstinence. After recoding these five cases as non-abstainers, an intervention effect was still evident, with $20.5 \%$ of the intervention group having abstained compared to $8.7 \%$ of the comparison group. Because the groups had marginally significant differences with regard to sex and amount smoked per day at baseline, a logistic regression procedure was done to assess group differences in abstinence after adjusting for these two variables. An effect of the intervention was still evident, with the comparison group being 2.5 times more likely than the intervention group to be smoking at the post-intervention assessment $(\mathrm{p}=0.014)$.

As a conservative approach to adjust for attrition effects, missing cases were included in a subsequent analysis after 
Table 2 Past-week abstinence rates by condition

\begin{tabular}{|c|c|c|c|c|}
\hline Sample/outcome & Intervention (\%) & Comparison (\%) & $\chi^{2}$ & $\mathrm{p}$ Value \\
\hline \multicolumn{5}{|l|}{ Longitudinal sample* (n=282) } \\
\hline Self reported abstinence & 21.2 & 11.3 & 5.11 & 0.024 \\
\hline Validated abstinence $\dagger$ & 20.5 & 8.7 & 8.01 & 0.005 \\
\hline \multicolumn{5}{|c|}{ Including missing cases $¥(n=313)$} \\
\hline Validated abstinence $\dagger$ & 17.3 & 8.3 & 5.72 & 0.017 \\
\hline \multicolumn{5}{|c|}{ Individual participants only ( $n=253$ ) } \\
\hline \multicolumn{5}{|c|}{ Validated abstinence $\dagger$} \\
\hline including missing cases $\ddagger$ & 18.9 & 7.1 & 7.71 & 0.006 \\
\hline
\end{tabular}

Table 3 Results of logistic regression analysis predicting validated past-week abstinence * from five variables $(n=280)$

\begin{tabular}{|c|c|c|c|}
\hline Predictor & $\begin{array}{l}\text { Adjusted } \\
\text { odds ratio }\end{array}$ & $95 \% \mathrm{Cl}$ & $\mathrm{p}$ Value \\
\hline Condition† & 0.37 & 0.171 to 0.786 & 0.010 \\
\hline Sex $\ddagger$ & 0.88 & 0.409 to 1.87 & 0.730 \\
\hline Amount smoked per day§ & 1.58 & 1.12 to 2.22 & 0.009 \\
\hline Minutes to first cigarette of the day 9 & 0.86 & 0.705 to 1.06 & 0.160 \\
\hline Number of recent quit attempts** & 0.88 & 0.714 to 1.09 & 0.242 \\
\hline \multicolumn{4}{|c|}{$\begin{array}{l}\text { *Coded as } 0 \text { (abstinent) or } 1 \text { (non-abstinent). } \\
\text { †Coded as } 0 \text { (comparison) or } 1 \text { (intervention). } \\
\text { †Coded as } 1 \text { (female) or } 2 \text { (male). } \\
\S \text { Response categories ranged from } 1 \text { ( } 0 \text { cigarettes on a typical day) to } 11 \text { (more than } 40 \text { cigarettes on a } \\
\text { typical day). } \\
\text { TResponse categories ranged from } 1 \text { (immediately after waking) to } 6 \text { (more than } 2 \text { hours after waking). } \\
{ }_{* *}^{*} \text { Actual number of attempts during the past } 3 \text { months. }\end{array}$} \\
\hline
\end{tabular}

being coded for non-abstinence. Validated abstinence rates including missing cases was about $17 \%$ in the intervention group compared to $8 \%$ in the comparison, a significant difference. Because the aggregation of some participants within households may have produced dependency in the data because of clustering among family members, ${ }^{31}$ the analysis was repeated including only individual participants (one family member was randomly selected from the family cluster to include in the analysis). A similar pattern was seen for these 253 smokers than was seen in the previous analyses: the validated abstinence rate including missing cases coded for nonabstinence was about $19 \%$ for the intervention group compared to $7 \%$ in the comparison group.

\section{Predictors of abstinence across condition}

To examine predictors of abstinence, univariate tests were conducted for the longitudinal sample to assess the relationship of validated past-week abstinence with sociodemographic and baseline smoking related variables. Sex, age, marital status, number of children at home, income, years of education, place of birth, acculturation level, age first started to smoke, number of years smoking, amount smoked per day, minutes to first cigarette of the day, number of recent quit attempts, knowledge, and self efficacy for quitting were tested. Univariate analyses showed that amount smoked per day, minutes to first cigarette of the day, and number of recent quit attempts were significantly related to validated abstinence $(p \leqslant 0.05)$. Heavier baseline smoking, fewer minutes to one's first cigarette of the day, and fewer recent quit attempts were associated with non-abstinence. A logistic regression analysis was conducted using these three smoking related predictors along with condition (intervention versus comparison) and sex to determine their independent association with abstinence. As shown in table 3, with all five variables in the model, only condition and amount smoked per day were significantly and independently associated with abstinence. Comparison group participants and heavier baseline smokers were at greater risk of being non-abstinent.

\section{Participation in intervention}

Participation in the seven intervention home and telephone sessions varied from $0-7$ sessions, with an average of 3.44 (3.25) sessions. The main analyses in the present study were done by intent-to-treat - that is, individuals assigned to the intervention group were analysed as such, even if they received none or only part of the intervention. However, it is also useful to examine if the dose of intervention was related to abstinence. With missing cases coded as non-abstinent, validated abstainers had participated in a greater average number of sessions (4.68) than non-abstainers (3.19) $(\mathrm{t}[147]=2.11, \mathrm{p}=0.037)$.

With regard to participation in the Helpline by the comparison group, objective verification of calls to the Helpline was not possible. However, an item on the post-intervention survey asked if the participant had called the Helpline in the last three months. Thirty six comparison group participants $(24 \%)$ reported that they had called the Helpline, a significantly higher proportion than intervention participants $(8 \%)$. Nevertheless, validated past-week abstinence among those comparison group participants who reported calling was similar to that of individuals in the comparison group who did not call, with rates of $8.3 \%$ and $8.8 \%$, respectively $\left(\chi^{2}[1]=0.007, \mathrm{p}=0.94\right)$. 


\section{DISCUSSION}

Results of this study showed a significantly higher postintervention smoking abstinence rate among Latino participants in a culturally appropriate smoking cessation programme than among participants referred to Spanish language Helpline. The intervention content was based on relevant social cognitive constructs, and was delivered by community lay health advisors, or promotores. Evidence for the intervention effect was seen in self reported abstinence, validated abstinence using exhaled carbon monoxide concentrations, and with dropouts recoded to non-abstinence. In all analyses, abstinence rates among intervention participants were at least twice as high as those of the comparison group.

Few of the sociodemographic and baseline smoking variables examined here predicted abstinence in the study sample, a surprising finding because several of these variables are reported elsewhere as predictors of cessation. For example, older age, ${ }^{32}$ male sex, ${ }^{32-34}$ higher education level, ${ }^{33}$ and knowledge about the effects of smoking ${ }^{35}$ have been associated with successful cessation. Having children in the home was expected to be associated with abstinence because of its previously reported association ${ }^{36}$ and because of the importance of family and responsibility to one's children in the Latino culture. Self efficacy for quitting has been a consistent predictor of abstinence in other studies, ${ }^{37}{ }^{38}$ although it failed to predict post-intervention outcome in the present study. It should be pointed out that most of these studies do not include Latinos, and little is known about the association of these variables with abstinence in Latinos. In addition, several measures in the present study, including self efficacy, were specifically designed for this study and population; therefore differences between these results and those of others could be caused by differences in measurement. Other biological and psychosocial variables such as nicotine withdrawal symptoms and depression were not measured, and may be important predictors of abstinence/relapse among Latinos. In the present study, the strongest independent predictor after controlling for condition was number of cigarettes smoked on a typical day. This variable is a reliable indicator of addiction to nicotine, ${ }^{39}$ and is a consistent predictor of abstinence in other

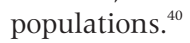

Several methodological and conceptual strengths of the study deserve mention. This is one of the few randomised studies of culturally appropriate smoking cessation interventions with minority populations. Although the lay health advisor approach has been used to educate, empower, and change infrequent or relatively straightforward behaviours, ${ }^{911}{ }^{14}$ this is a rare application of the approach to a complex addictive behaviour. Inadequate sample sizes are frequently a problem in smoking research. The number of participants in the present study was greater than in other studies with Latino smokers, ${ }^{81}$ ensuring adequate statistical power to detect an overall intervention effect. Use of exhaled carbon monoxide as biochemical validation of abstinence also was a strength, insofar as others have reported the need to confirm self reports of abstinence among smokers participating in intervention research..$^{28}$ Finally, the dropout rate was low and attrition did not appear to introduce an important bias.

\section{Study limitations}

Despite the strengths, there are several limitations of the study. The present study was an efficacy trial, appropriately concerned with determining whether the general approach worked at all. Therefore, we did not conduct an evaluation of which intervention components were responsible for the success of the programme. ${ }^{42}$ Future construct and external validity studies will need to explore systemically which components, under what conditions, and for whom the approach works. ${ }^{42}$ As in all social/behavioural research, there may have

\section{What this paper adds}

Randomised studies of culturally appropriate smoking cessation interventions with Latinos are rare. One of the few was an assessment of a culturally specific multicomponent behavioural programme with 93 Hispanic smokers in Queens, New York. Compared to a minimal contact control group, intervention participants showed greater cotinine validated abstinence rates at post-test. However, by the 12 month follow up, quit rates for the two groups had converged.

The purpose of the present study was to add to the scant body of knowledge about effective smoking cessation programmes for Latinos by evaluating the impact a culturally appropriate (for example, promotor delivered) smoking cessation intervention. About one week post-intervention, validated (carbon monoxide) past-week abstinence rates were more than twice as high in the intervention group than in the comparison group referred to a smokers' Helpline. The culturally appropriate intervention facilitated abstinence in Latino smokers, at least in the short term.

been a selection bias, as participation was voluntary and participants were likely to be motivated to quit. Therefore, generalisation of results to all types of smokers (for example, those less motivated, various Latino subgroups) cannot be assumed. The intervention assumed that all the participants progress at the same pace from one visit to the other. A longer intervention with more individualised visits could strengthen the intervention effect, as could adjunctive tailored pharmacological treatment. However, more intensive intervention may not be practical or more effective given that smokers in the present study participated in about half of the intervention sessions on average. Objective verification of calls to the Helpline by the comparison group participants was not possible, and the $24 \%$ call rate may be an overestimate. Findings suggest that participation aided short term abstinence, yet relapse is likely over time and the longer term effects of the programme are not known. Nevid and Javier ${ }^{8}$ recently reported promising results at post-treatment of a culturally specific multicomponent smoking cessation intervention for Hispanics. However, by the 12 month follow up, rates had declined in the treatment group to be near equal those of a self help comparison group. The longer term effect of the promotor approach should be studied, and its public health potential for Latino smokers relative to other approaches is clearly worth further study.

\section{ACKNOWLEDGEMENTS}

The authors gratefully acknowledge the efforts and contribution of Ilia Rolón, Gabriela Villavicencio, Veronica Serrano, Teresa Aparicio, Nadia Campbell, Maria Lara-Carvalho, Violeta Macias, Leticia Lleva, and the Proyecto Sol recruiters and promotores. This research was supported by a grant from the California Tobacco-related Disease Research Program (TRDRP), grant 6PT-2001(H).

Authors' affiliations

S I Woodruff, G A Talavera, J P Elder, Graduate School of Public Health, San Diego State University, San Diego, California, USA

\section{REFERENCES}

1 US Department of Health and Human Services. Tobacco use among U.S. racial/ethnic minority groups: African Americans, American Indians and Alaska Natives, Asian Americans and Pacific Islanders, Hispanics. A report of the Surgeon General, 1998. Atlanta, Georgia: Centers for Disease Control and Prevention, Office on Smoking and Health, 1998. (US Government Printing Office Publication No S/N 017-001-00527-4.)

2 Centers for Disease Control. Cigarette Smoking among adults - United States, 1998. MMWR Morb Mortal Wkly Rep 2000;49:881-4. 
3 Pierce JP, Gilpin EA, Emery SL, et al. Tobacco control in California: who's winning the war? An evaluation of the Tobacco Control Program 1989-1996. La Jolla, CA: University of California, San Diego, 1998.

4 Zhu S-H, Rosbrook B, Anderson C, et al. The demographics of help-seeking for smoking cessation in California and the role of the California Smokers' Helpline. Tobacco Control 1995;4(supp 1):S9-15.

5 Fiore MC, Bailey WC, Cohen SJ, et al. Treating tobacco use and dependence. Clinical practice guideline. Rockville, Maryland: US Department of Health and Human Services, Public Health Service, June 2000.

6 Cohen RE. Principles of preventive mental health programs for ethnic minority populations: the acculturation of Puerto Ricans to the United States. Am J Psychiatry 1972;128:79-83.

7 Abad V, Ramos J, Boyce E. A model for delivery of mental health services to Spanish-speaking minorities. Am J Orthopsychiatry 1974:44:584-95.

8 Nevid JS, Javier RA. Preliminary investigation of a culturally specific smoking cessation intervention for Hispanic smokers. Am J Health Promo 1997;11:198-207.

9 Baker EA, Lowell ME. The Latino health advocacy program: a collaborative lay health advisor approach. Health Educ Behav 1997:24:495-510.

10 Werner D. The village health worker: lackey or liberator? World Health Forum 1981;3:46-68.

11 Watkins EL, Harlan C, Eng E, et al. Assessing the effectiveness of lay health advisors with migrant farmworkers. Fam Community Health $1994 ; 16: 72-87$

12 Meister JS, Warrick LH, Zapién JG, et al. Using lay health workers: case study of a community-based prenatal intervention. J Community Health 1992;17:37-51

13 Vellozzi CJ, Romans M, Rothenberg RB. Delivering breast and cervical cancer screening services to underserved women: part I. Literature review and telephone survey. Women's Health Issues 1996;6:65-73.

14 Navarro AM, Senn KL, Kaplan RM, et al. Por La Vida intervention model for cancer prevention in Latinas. J Natl Cancer Inst Monogr 1995:18:137-45

15 Castro F, Elder J, Coe K, et al. Mobilizing churches for health promotion in Latino communities: Compañeros en la Salud. J Natl Cancer Inst Monogr 1995; 18:127-35.

16 Alcalay R, Alvarado M, Balcazar H, et al. Salud para su Corazon: a community-based Latino cardiovascular disease prevention and outreach model. J Community Health 1999;24:359-79.

17 Bruhun JG, Brandon JE. Border health: challenges for the United States and Mexico. Garland Publishing, 1997.

18 Marín, G. AIDS prevention among Hispanics: needs, risk behaviors, and cultural values. Public Health Rep 1989;104:411-15.

19 Marín G, Marín BV. Research with Hispanic populations. Applied Social Research Methods Series, vol 23. London: Sage Publications, 1991.

20 Bandura A. Social foundations of thought and action: a social cognitive theory. Englewood Cliffs, New Jersey: Prentice Hall, 1986.

21 Marín G, Marín BV, Otero-Sabogal R, et al. The role of acculturation on the attitudes, norms and expectancies of Hispanic smokers. J Cross Cult Psychol 1989;20: 399-415.

22 Marín BV, Marín G, Peréz-Stable EJ, et al. Cultural differences in attitudes toward smoking: developing messages using the theory of reasoned action. J App/ Social Psychol 1990;20:478-93.
23 Marín BV, Peréz-Stable EJ, Marín G, et al. Attitudes and behaviors of Hispanic smokers: implications for cessation interventions. Health Educ $Q$ 1990; 17:287-97

24 Peréz-Stable EJ, Marín G, Posner SF. Ethnic comparison of attitudes and beliefs about cigarette smoking. J Gen Intern Med 1998;13:167-74

25 Pérez-Stable EJ, Marín G, Marín BV. Rompa con el vicio: Una guía para dejar de fumar. NIH Publication No. 94-3001. US Department of Health and Human Services, National Cancer Institute, 1994

26 Zhu S-H, Stretch V, Balabanis M, et al. Telephone counseling for smoking cessation: effects of single-session and multiple-session interventions. J Consult Clin Psychol 1996:64:202-11.

27 Becoña E, Vázquez FL. Self-reported smoking and measurement of expired air carbon monoxide in a clinical treatment. Psychol Rep 1998;83:316-18.

28 Coultas DB, Howard CA, Peake GT, et al. Discrepancies between self-reported and validated cigarette smoking in a community survey of New Mexico Hispanics. Am Rev Respir Dis 1988;137:810-14.

29 Cuellar I, Arnold B, Maldonado R. Acculturation rating scale for Mexican Americans-ll: a revision of the original ARSMA scale. Hisp J Behav Sci 1995; 17:275-304.

30 Biglan A, Hood D, Brozovsky P, et al. Subject attrition in prevention research. In: Leukefeld CG, Bukoski WJ, eds. Drug abuse prevention intervention research: methodological issues. NIDA Research Monograph 107, 1991:213-34

31 Donner A, Klar N. Design and analysis of cluster randomization trials in health research. London: Arnold, 2000

32 McWhorter WP, Boyd GM, Mattson ME. Predictors of quitting smoking: the NHANES I followup experience. J Clin Epidemiol 1990;43:1399_ 405

33 Bjornson W, Rand C, Connett JE, et al. Gender differences in smoking cessation after 3 years in the lung health study. Am J Public Health 1995:85:223-30.

34 Ward KD, Klesges RC, Zbikowski SM, et al. Gender differences in the outcome of an unaided smoking cessation attempt. Addict Behav 1997:22:521-33.

35 Halpern MT. Effect of smoking characteristics on cognitive dissonance in current and former smokers. Addict Behav 1994;19:209-17.

36 Halpern MT, Warner KE. Motivations for smoking cessation: a comparison of successful quitter and failures. J Subst Abuse 1993.5:247-56

37 Gulliver SB, Hughes JR, Solomon LF, et al. An investigation of self-efficacy, partner support and daily stresses as predictors of relapse to smoking in self-quitters. Addiction 1995;90:767-72.

38 Haaga DA, Stewart BL. Self-efficacy for recovery from a lapse after smoking cessation. J Consult Clin Psychol 1992;60:24-8.

39 Heatherton TF, Kozlowski LT, Frecker RC, et al. The Fagerstrom test for nicotine dependence: a revision of the Fagerstrom tolerance questionnaire. Br J Addict 1991;86:1119-27.

40 Farkas AJ, Pierce JP, Zhu SH, et al. Addiction versus stages of change models in predicting smoking cessation. Addiction 1996;91:1271-80.

41 Muñoz RE, Marín BV, Posner SF, et al. Mood management mail intervention increases abstinence rates for Spanish-speaking Latino smokers. Am J Commun Psychol 1997;25:325-43.

42 Flay BR. Efficacy and effectiveness trials (and other phases of research) in the development of health promotion programs. Prev Med $1986 ; 15: 451-74$

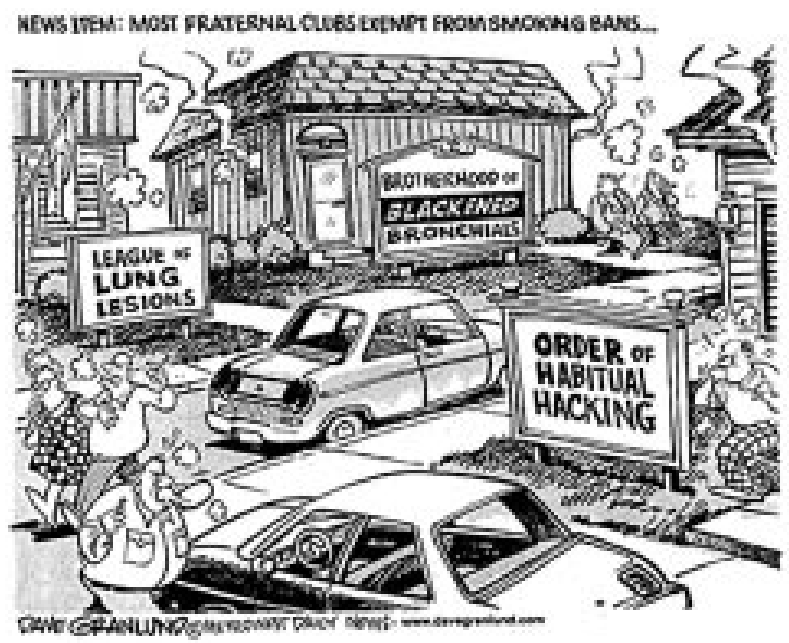

(c) Dave Granlund. Metrowest Daily News. www.davegranlund.com 